\title{
TEATRO DE RUA COMO APROPRIAÇÃO DA SILHUETA URBANA: HIBRIDISMO E JOGO NO ESPAÇO INÓSPITO
}

\author{
André Luiz Antunes Netto CARREIRA ${ }^{1}$
}

- RESUMO: Pretende-se refletir aqui sobre a exploração de fronteiras no campo do teatro a partir da utilização do conceito de risco. A experimentação de técnicas de risco na preparação do ator e na construção do texto espetacular se orienta à criação de cerimônias teatrais cujo eixo é a constituição de novos vínculos entre a audiência e a performance.

- PALAVRAS-CHAVE: Teatro; risco; jogo; pós-modernidade.

Quando o grupo norte americano Living Theatre percorreu a Europa nos anos 70, abriu uma discussão sobre os sentidos possíveis para o espetáculo ao ar livre num mundo que começava a se aproximar do conceito de mundialização. Espetáculos como Seis atos públicos, com seus recorridos procissionais, e $A$ torre do dinheiro, com sua estrutura de vários metros de altura, propunham um novo olhar sobre a tradição do fenômeno teatral de rua. A experiência do grupo criado por Julian Beck e Judith Malina deve ser pensada a partir da referência da tradição medieval do teatro ao ar livre com caráter explicitamente religioso e também das experiências político-espetaculares da Rússia dos bolcheviques e da Alemanha antes da eclosão do nazismo. Apesar de o fenômeno teatral de rua ter se transformado e se multiplicado em diferentes direções, é interessante notar que, a partir dos anos 70, se instalaram, na Europa, idéias renovadoras sobre essa modalidade teatral. Paradoxalmente, os discursos, eminentemente politizados e militantes, que dominavam o mundo das

1 Professor do Centro de Artes da Universidade do Estado de Santa Catarina - UDESC - 88035-001 Florianópolis - SC. 
idéias, não foram os que deixaram marcas mais profundas nas práticas teatrais de rua que perduraram e fundamentaram a renovação teatral do espaço da rua que observamos nos anos 80-90. Nos discursos teatrais dos grupos de rua da América Latina, nota-se uma ausência de projetos estéticos que propõe uma reflexão. A partir do final dos anos 70, o desequilíbrio entre a missão social e política e a reelaboração de linguagens teatrais condenou muito desses grupos à perda de referencial artístico e à defasagem com a época. É interessante observar que esses grupos, em sua maioria, não propunham uma ampliação e transformação dos sentidos dos espaços urbanos, senão uma adaptação do discurso teatral às condições sociais e físicas da rua, preocupados quase exclusivamente com o nível temático dos espetáculos. Consideravam o espaço da rua apenas no nível dos objetivos políticos como lugar de encontro com o público. Paulatinamente, impregnados por dados culturais próprios do período histórico, os grupos setentistas incorporaram a idéia de comunhão e, assim, o espaço da rua passou também a significar o palco de um novo tipo de relação que estava marcado por sentidos ritualísticos, conservando ao mesmo tempo seu caráter político. Esse sentido de comunhão, pode ser visto como uma compreensão das potencialidades do espaço da rua. Assim, a rua não seria um lugar para o contato com o público apenas no sentido da difusão de idéias políticas, mas sim da constituição de práticas de ressignificação dos referentes culturais, da ruptura das distâncias impostas pelas instituições. No entanto, é possível dizer que esse pensamento não foi articulado com um novo olhar sobre a capacidade de significação do espaço da rua. Não houve ainda um desenvolvimento extensivo dessa relação no contexto do teatro latino-americano e particularmente no Brasil. É esse o aspecto que este artigo busca explicitar e discutir. A matriz dessas experiências, citadas anteriormente, sugere a possibilidade de pensar o teatro de rua a partir da idéia da abordagem do espaço urbano, para permitir uma aproximação a essa modalidade teatral que não seja regida apenas pela delimitação dos conteúdos temáticos e pela citação de referentes culturais tradicionais, mas por suas regras de funcionamento como espetáculo e pelo seu papel na reorganização do espaço urbano. O teatro de rua é uma forma espetacular que nasce do assalto à silhueta urbana. A idéia de silhueta urbana diz respeito aos aspectos físicos da cidade, mas também, e principalmente, ao complexo de relações sociais que nascem do uso desse espaço. Conseqüentemente, a interferência teatral nessa rede de construções simbólicas, que se articulam no espaço urbano, produz uma profunda ressignificação desse espaço e constrói o plano da cerimônia social que é o próprio espetáculo teatral. 


\section{A rua como espaço social e lugar do jogo}

Para realizar um estudo do teatro de rua, é interessante, em primeiro lugar, repensar o espaço que contém essa manifestação espetacular. É necessário delimitar o funcionamento da rua e estabelecer como se dão as conexões dos usos sociais da rua e o teatro que faz dela seu palco. Roberto Lobato Corrêa (1989) define a grande cidade capitalista como um conjunto de diferentes usos justapostos entre si. Esse espaço se define por ser: simultaneamente fragmentado e articulado, cada uma de suas partes mantém relações espaciais com as demais, ainda que de intensidade muito variável. Essas relações manifestam-se empiricamente por meio de fluxos de veículos e de pessoas associados às operações de carga e descarga de mercadorias, aos deslocamentos cotidianos entre as áreas residenciais e os diversos locais de trabalho, aos deslocamentos menos freqüentes para compras no centro da cidade ou nas lojas do bairro, às visitas aos parentes e amigos, e às idas ao cinema, culto religioso, praias e parques. Quando pensamos na complexidade de usos dos espaços da cidade, já estamos colocando nossa atenção nas práticas de significação que articulam os sentidos da rua dentro do marco cultural no qual esta está inserida. É nesse contexto que podemos refletir a relação teatro de rua/teatro popular. Talvez não seja uma novidade propor clara diferenciação entre a idéia de teatro popular e do teatro de rua. De forma reiterada, estudiosos do teatro se referem ao teatro de rua como um componente do teatro popular. Mas de fato, quando nos debruçamos sobre o teatro de rua contemporâneo podemos ver uma miríade de projetos cênicos que exploram formas teatrais que se relacionam muito mais com experimentações vanguardistas do que com a cultura popular. No entanto, quando percebemos a rua como um lugar da cultura popular nos inclinamos a pensar que as manifestações espetaculares nesse âmbito devem estabelecer relações com esse campo cultural que delimitamos como popular. Mas se há um vínculo entre o campo da cultura popular e o teatro de rua, esse vínculo se manifesta mais pela penetração dos sentidos do uso da rua, na possibilidade de apropriação e transformação dos usos da rua, até mesmo em uma lógica da rua, e não necessariamente no uso dos referentes estéticos das formas culturais tradicionais ou na relação exclusiva com os padrões socioeconômicos marginalizados. A rua, como espaço de convivência, permite que o cidadão desfrute de um anonimato que o libera do peso do compromisso pessoal. No espaço aberto da rua e em comunidade, o sujeito urbano se sente mais capaz de atuar. Esse é um comporta- 
mento que facilita que na rua exista uma predisposição para o jogo e a participação espontânea. Participação espontânea se refere aqui não necessariamente a uma inclusão do público na cena, mas na disponibilidade de se relacionar de múltiplas formas com o espetáculo, aceitando a invasão do espaço coletivo.

O jogo foi definido pelo sociólogo francês Jean Duvignaud (1982) "como uma atividade sem objetivos conscientes, um estado de disponibilidade que foge a toda intenção utilitária" (p.41), livre e sem regras "neste estado de ruptura do ser individual ou social, no qual a única coisa que não se questiona é a arte" (p.35). O jogo é brincadeira, é fantasia. As crianças fazem da calçada de sua rua a praia à qual chegam piratas. Os adultos transformam, durante uma festa de Carnaval, as pedras do calçamento no âmbito onde cada um pode ser o que quiser. A rua, é portanto, o espaço para o exercício da liberdade e da criatividade. No que se refere ao comportamento do homem da rua, convivem duas tendências: a primeira é uma atitude de respeito às regras sociais dominantes, a segunda é a abertura ao jogo e à liberdade de ação. $\mathrm{O}$ equilíbrio entre a atitude social dominante e o jogo é dinâmico, e se modifica de acordo com os processos socioculturais do momento. Na rua existe um complexo jogo social no qual está presente uma infinidade de inter-relações que regem grande parte do comportamento dos cidadãos. Esse ordenamento não é imutável, e portanto, é permeável à ação coletiva anteriormente descrita e se transforma segundo a incidência dos acontecimentos. Sua dinâmica pode parecer à simples vista muito lenta, mas sob o imperativo dos processos sociais e políticos pode ser extremamente rápida e surpreendente tendência ao jogo se vê favorecida especialmente pela individualização, que é provocada pela sensação de liberdade. Paradoxalmente, é pelo jogo da rua - manifestado nas ações coletivas - que o indivíduo se expressa sem freios e limitações. O jogo quando "evolui da sua esfera de fenômeno subjetivo individual e penetra as estruturas da vida social (Duvignaud, 1982, p.54)" se faz transgressor, porque a mobilização da energia lúdica coletiva questiona os códigos e as regras sociais estabelecidas. Ao se materializar na superfície do ser social, o jogo se plasma em manifestações culturais de ruptura da ordem vigente. Esse jogo da rua, cujo exemplo mais contundente talvez seja o Carnaval, abre a possibilidade da mais ampla liberdade criadora, porque, enquanto dura, põe o mundo de cabeça para baixo, inverte todos os valores. Nossa sociedade estabeleceu como regra que as ruas cumprem uma série de funções específicas, e aquelas atividades que extrapolam esses limites entram numa zona de conflito, pois questionam não somente o uso da rua, mas também o poder de controle 
sobre o espaço cidadão. O jogo, enquanto experiência lúdica, é em essência questionador. Subverte a ordem que propicia tranqüilidade e a desequilibra. É essa a característica que define o jogo como um elemento perigoso que deve ser enquadrado como um fenômeno temporário para seu controle. Jean Duvignaud (1982) fazendo referência ao jogo com relação às festas como acontecimentos únicos, diz: "Durante esta explosão súbita e momentânea das relações humanas estabelecidas, rompe-se o consenso, apagam-se os modelos culturais transmitidos de geração em geração, não por uma transgressão qualquer, mas porque o ser descobre, às vezes com violência, uma plenitude ou uma superabundância proibida na vida cotidiana lógico; a festa não dura. É perecível no seu próprio princípio" (p.34). No Carnaval, as mais amplas liberdades estão contidas em quatro dias.

As manifestações políticas de rua não controladas por aparelhos políticos, quando alcançam o grau de revolucionárias, isto é, quando põem em risco o sistema de dominação sociopolítico, atingem a mesma liberdade do Carnaval, pois as regras desaparecem e a criatividade se faz livre. Nesse caso, independentemente dos objetivos específicos da manifestação, aparece uma enorme variedade de reações que estão muito mais relacionadas com a possibilidade de jogar, seja o papel de transformador da realidade, seja simplesmente pôr para fora uma energia por muito tempo contida. É essa característica rupturista, própria do comportamento oriundo do jogo, que faz que o espaço da rua seja considerado estratégico pelos organismos encarregados de manter a ordem social. Por isso, o teatro de rua, ainda que não possa alcançar a dimensão do descontrole do Carnaval ou a força avassaladora das grandes manifestações sindicais, explicita a possibilidade de ruptura ao provocar o jogo e ao convidar os transeuntes a participar da criação - ainda que momentânea - de uma nova ordem. Isso ganha importância por se tratar de um fenômeno instalado em um espaço de vivência cotidiana - que diferentemente das salas teatrais - que não enclausura os espectadores, mas que, ao ser totalmente aberto, estreita a relação entre o acontecimento teatral e o horizonte da cidade, provocando um imediato desdobramento dos signos propostos pelo espetáculo.

\section{Os vínculos com a cultura popular}

Considerando a cultura popular como um conjunto de produção simbólica que se constrói também como imagem especular da cultura 
culta, uma questão pertinente, segundo Fredric Jameson, seria averiguar se ambos os movimentos culturais não se definem apenas como coisa relacionada com este outro. Então a cultura da rua que se relaciona estreitamente com a idéia de jogo aparece delimitada pelas fronteiras da cultura de entre muros, a cultura da instituição do interior dos edifícios. É o adentro e o afora que permitirão a construção de um saber/fazer diferenciado. A rua, por ser o espaço da circulação pública, onde estão desde o marginal até o trabalhador de setores médios, constitui um espaço de hibridação de usos que dá forma a um marco cultural próprio, mas que se relaciona - por aproximação - com o campo da cultura popular. É nesse território híbrido que se dá a aproximação entre o teatro de rua e a cultura popular. De fato, essa aproximação não é somente temática. Pelo contrário, ela se dá no terreno das regras de funcionamento do espetáculo e das modalidades de atenção do público. Isto é, a interferência da audiência tem, nesse caso, uma influência muito grande na constituição do espetacular. Quando falo da audiência (de sua interferência), quero dizer que, por meio das atitudes do público, surge um vetor que representa necessariamente a presença da cultura da rua/popular na cerimônia espetacular. Como o fazer espetacular não pode desconhecer a força do público na articulação de sentidos do espetáculo, o resultante do teatro de rua terá sempre o elemento popular no seu bojo, ainda quando não o tenha - conscientemente - na sua temática. Poderíamos dizer que o popular estaria sempre relacionado com o teatro de rua na sua existência como cerimonia social, como acontecimento.

\section{O teatro de rua como transgressão}

A hierarquização espacial que estabelece a cidade capitalista considera alguns espaços como nobres e outros como marginais. Ao confinar o espetáculo teatral nas salas, a cultura capitalista determinou que este aceitaria perder seu caráter de festa e ganharia o valor de mercadoria. Essa mercadoria tem mais valor nos espaços fechados onde o pagamento de uma entrada não somente gera lucro, como também outorga hierarquia. Nesse marco, a manifestação teatral na rua ocupa, cada vez mais, um espaço de marginalidade. A expressão dessa marginalidade denuncia a cara segregacionista do sistema e, portanto, o questiona, transgredindo assim as regras do uso espacial da cidade. Se o espaço profano da rua está reservado especialmente para suas funções específicas, toda atividade que esteja fora desse marco resultará, de certo modo, transgressora. Essa 
transgressão pode variar segundo graus ou intensidades, mas, ao fim, questionará o sistema dominante. Ainda quando a cultura dominante possa conviver com essa transgressão, cedendo alguns espaços, a expressão da rua continua sendo marginal ante o conceito de teatro respeitável que forjou a sociedade. José Guilherme Merquior, filósofo brasileiro, diz que "a arte tolerada pode gerar a crítica da sociedade que a tolera e segregar o vírus de ruptura com dita sociedade" (1974, p.102). Que a sociedade tolere o teatro de rua não o faz menos transgressor, porque essa tolerância está marcada por uma atitude discriminatória que permanentemente situa esse teatro no seu lugar de marginalidade, que é um lugar de enfrentamento com o padrão cultural dominante. O simples fato de o teatro de rua existir implica um potencial transgressor, mas a concretização dessa transgressão se manifesta em diferentes ordens. Em primeiro lugar, o teatro de rua transgride o caótico deslocamento das pessoas na ruas, pois, ainda que momentaneamente, propõe uma ruptura no uso cotidiano da rua. Recria o espaço da rua e inventa uma nova ordem, ao mesmo tempo que impõe às pessoas que caminham pela rua uma mudança: de simples pedestres a espectadores. Em segundo lugar, ao ocupar a rua, o teatro se faz permeável à influência do que se poderia chamar cultura da rua, que seria a mescla de todas as culturas dos usuários do espaço da rua, tudo aquilo que se manipula como modo de atuar próprio da rua: os medos, os códigos gestuais, as formas de ocupação do espaço etc. Essa cultura da rua estaria situada fora do padrão cultural dominante, como fato paralelo e marginal. Outro aspecto dessa transgressão: o teatro de rua toma elementos das manifestações de rua, especialmente aquelas relacionadas com as lutas políticas ou sindicais. Esse fenômeno responde ao que, no seio dessas manifestações, se desenvolveu numa maneira particular de ocupação e uso do espaço da rua que explicita o caráter democrático da rua. $\mathrm{O}$ teatro de rua, tão transgressor como as lutas políticas, toma emprestado a estas alguns elementos formais. Ainda que se possam ver nas ruas manifestações artísticas que nada têm de transgressoras - especialmente naqueles casos em que as instituições da cultura levam espetáculos de âmbitos fechados aos palcos na rua, ou quando organismos oficiais de cultura realizam atividades de rua -, pode-se dizer que essencialmente o teatro de rua transgride o princípio hierárquico espacial dentro do qual a sociedade burguesa enquadra as manifestações artísticas. $\mathrm{O}$ teatro de rua será sempre um acontecimento com uma composição híbrida, estará sempre em contato com os referentes da cultura culta e da popular. O hibridismo é uma característica fundamental da rua que é o âmbito que permite e fomenta a interferência múltipla de fatores na cons- 
trução do espetáculo de rua como cerimônia pública. A ampla diversidade de sujeitos sociais que estão aptos a interferir na construção do momento espetacular modifica o caráter do espetáculo, senão na totalidade da sua linguagem cênica, na sua relação concreta com o ambiente. Utilizando termos da semiótica, poderíamos dizer que até o significante do signo teatral sofre influências modificadoras na rua, dado que as próprias regras que são propostas para a construção do espetáculo podem mudar (e mudam) radicalmente na relação vigorosa que se estabelece na representação de rua. A interferência do público multifacético (multissocial) da rua tem a potencialidade de transformar o caráter do espetáculo teatral, incorporando componentes da cultura popular e construindo no evento espetacular um acontecimento da cultura popular. Um encontro entre realizadores e audiência, que também pode se dar entre campos culturais distintos, mas que se constrói como uma síntese cujo resultante é a reapresentação da cultura popular, ou mais especificamente um exercício de reelaboração que funde esta com os referenciais da tradição teatral ocidental. Ao construir sentidos atribuindo significados ao espetáculo, a cultura de rua define o teatro de rua como acontecimento que se incorpora a esse marco cultural. Então, seria possível pensar que mesmo o espetáculo mais experimental viria a interagir com a cultura popular, compondo um objeto que é apropriado pelo olhar de quem está na rua, ou mais especificamente pela cultura híbrida das ruas.

\section{Conclusão}

Com base nos conceitos explicitados anteriormente, poderíamos pensar que seria mais apropriado trabalhar com a idéia de que a rua realmente significa, no caso da expressão "teatro de rua", todos aqueles espaços públicos que não são salas convencionais para representações teatrais (tenham estas palco italiano ou não). Trabalhar com a delimitação de espaços não convencionais - lugares da cidade -, como uma ampliação dos conceitos de teatro de rua ou de praça, nos permite conservar a percepção das regras de uso da rua e suas influências nos processos criadores de uma ampla gama de espetáculos cênicos. Refletir sobre o teatro como exercício de apropriação da silhueta urbana, como prática de enfrentamento com o espaço inóspito, nos obriga a um deslocamento (reposicionamento) do nosso olhar. Esse novo ponto de vista situará, necessariamente, o estudo ou até mesmo a realização do teatro nos espaços não convencionais em um campo que já não será apenas o de uma 
modalidade de teatro popular. Será visto como um âmbito híbrido no qual se fusionam dinamicamente elementos da cultura popular com dados da tradição do teatro ocidental.

CARREIRA, A. L. A. N. Street theater as appropriation of the urban silhouette. Trans/Form/Ação (São Paulo), v.24, p.143-152, 2001.

- ABSTRACT: The aim is to study the exploration of frontiers in the field of theater, on the basis of the concept of risk. The experimentation of risk technics in the preparation of the actor and in the construction of the spectacle text is oriented towards the creation of theatrical ceremonies whose axis is the constitution of new links between the audience and the performance.

- KEYWORDS: Theater; risk; game; post-modernity.

\section{Referências bibliográficas}

AMMANN, A. B., BAREI, S. N. El teatro callejero: un rescate de lo popular. In: Reflexiones sobre teatro latinoamericano del siglo veinte. Buenos Aires: Galerna, Lenck Verlag, 1989.

AVILA, A. O lúdico e as projeções do mundo do barroco. São Paulo: Perspectiva, 1980.

BARTHES, R. Mitologias. México: Siglo Veintiuno, 1988.

BENÍCIO, E. Teatro de rua do Nordeste do Brasil: uma forma de teatro popular. São Paulo, 1991. Dissertação (Mestrado) - Universidade de São Paulo.

BOAL, A. Tecnicas latinoamericanas de teatro popular. Buenos Aires: Corregidor, 1975.

CARREIRA, A. Teatro de rua depois dos anos de autoritarismo. Revista Cadernos de Classe (Brasília), n.0, 1988.

. El teatro callejero. El Otro Teatro. Buenos Aires. Libros del Quirquincho, 1990.

. Teatro callejero en la ciudad de Buenos Aires después de la dictadura militar. Latin American Theatre Review, v.27, n.2, 1994a.

. El teatro callejero en la Argentina y en el Brasil democraticos de la década del '80 (La pasión puesta en la calle). Buenos Aires, 1994b. Tese (Doutorado) - Universidad de Buenos Aires. (no prelo).

COHEN, D., GREENWOOD, B. The Buskers: A History of Street Entertainment. London: David Charles Inc, 1981. 
CORRÊA, R. L. O espaço urbano. São Paulo: Ática, 1989.

CRUCIANI, F., FALLETTI, C. El teatro de Calle. Técnica y manejo del espacio. México: Gaceta/CECILT, 1992.

DE MARINIS, M. El nuevo teatro. Barcelona: Paidós, 1988.

DUVIGNAUD, J. Espectaculo y sociedad. Caracas: Tiempo Nuevo, 1970. El sacrificio inutil. México: Fondo de Cultura Económica, 1979. El juego del juego. México: Fondo de Cultura Económica, 1982.

FERRARA, L. D. 1981. A estratégia dos signos. São Paulo: Perspectiva, 1981.

FRENCH, W. W. Rich joy of the sixties: the street of New York City as theatrical space. The Teatrical Space. Cambridge: Cambridge University Press, 1987.

GARCÍA CANCLINI, N. Culturas hibridas. México: Grijalbo, 1989.

GARCIA, S. Teatro da militância. São Paulo: Perspectiva, 1990.

GUIMARÃES, C., GONDIM, J. C., VANDEBENQUE, G. Tá na rua: um teatro que descoloniza. Cadernos do Terceiro Mundo, ago.-set. 1982.

JAVIER, F. La renovación del espacio escénico. La Plata: Fundación Banco de la Provincia de Buenos Aires, 1981.

KUNER, M. C. Street theatre, from entertainment to protest, the 1960's to 1970's. In: Maske Und Kothurn. Wien: Jahrgang-Böhlau Verlag, 1987.

LANGSTED, J. Is street theatre theatre? In: Maske Und Kothurn. Wien: Jahrgang: Böhlau Verlag, 1987.

MERQUIOR, J. G. Formalismo e tradição moderna: o problema da arte na crise da cultura. São Paulo: Forense, 1974.

MUMFORD, L. La ciudad en la historia: sus orígenes, transformaciones y perspectivas. Buenos Aires: Infinito, 1962.

RISSO PATRÓN, C. Apuntes de teatro callejero. Revista Espacios (Buenos Aires), v.5, n.10, oct. 1991.

SAARINEN, E. La ciudad: su crecimiento, su declinación y su futuro. México: Limusa, Wiley, 1967.

VAN ERVEN, E. Street theater in New York city in the 1980s: a choice of locus within the dramatic spectrum. In: Within The Dramatic Spectrum. USA: University Press of America, Inc, 1986.

WEISMAN, J. Guerrilla theatre: scenarios for revolution. New York: Anchor Books, 1973. 